\section{A study about the measurement method of the homogeneity of radioactivity along an iridium-192 wire used in brachytherapy}

\begin{abstract}
The Nuclear and Energy Research Institute has produced, since 1998, iridium-192 wires used in low dose rate brachytherapy. In the paper the authors studied the influence of wire profile on the homogeneity distribution of radioactivity of iridium-192 along the wire. The authors propose the improvements in the quality control procedure that will provide more accurate measurement data and suggest changes in control devices.
\end{abstract}

Key words: iridium-192 $\bullet$ iridium wire $\bullet$ low dose rate brachytherapy $\bullet$ quality control $\bullet$ cancer treatment $\bullet$ radioactive sources production

O. L. Costa ${ }^{\bowtie}$, W. A. P. Calvo, C. A. Zeituni,

M. E. C. M. Rostelato, J. A. Moura, A. Feher, C. D. Souza, S. L. Somessari

Nuclear and Energy Research Institute

(IPEN/CNEN-SP),

Radiation Technology Center (CTR),

2242 Prof. Lineu Prestes Ave.,

05508-000, São Paulo, SP, Brazil,

Tel.: +55113133 9821, Fax: +55113133 9765,

E-mail: olcosta@ipen.br

Received: 27 August 2013

Accepted: 27 January 2014

\section{Introduction}

Brachytherapy uses radioactive sources that are placed within the volume of tissue being treated, or adjacent to the volume [1]. Among the radionuclides used in brachytherapy iridium-192 distinguishes itself by advantageous physical characteristics as the half-life of 74 days and an average energy of $380 \mathrm{keV}$ [2]. The Radiation Technology Center of the Nuclear and Energy Research Institute (CTR-IPEN) have produced commercially iridium-192 wires used in low dose rate (LDR) brachytherapy since 1998 [3].

\section{Materials and methods}

For the production of iridium-192 wire, a platinum-iridium (25\% Pt, $75 \%$ Ir) wire (Goodfellow), $50 \mathrm{~cm}$ long and $0.1 \mathrm{~mm}$ in diameter is used. The overall diameter of the wire of $0.3 \mathrm{~mm}$ results in a platinum sheath of $0.1 \mathrm{~mm}$ thick. The wire is wound in helical form and inserted into an aluminum tubular shape capsule with $2 \mathrm{~cm}$ in diameter and $7 \mathrm{~cm}$ in height. The capsule is sealed and irradiated in the IEA-R1 nuclear reactor under a neutron flux of $5 \times 10^{13} \mathrm{n} \cdot \mathrm{cm}^{-2} \cdot \mathrm{s}^{-1}$ for a period of $30 \mathrm{~h}$. After irradiation, the wire is cooled for 30 days. By this means the main contaminants (Ir-194, Pt-197, Pt-199) are reduced. After the cooling period, the capsule containing the wire is brought into a hotcell with $5 \mathrm{~cm}$ lead wall, where it is cut and iridium wire is removed, then the measurement of radioactivity homogeneity is carried out. The wire is inserted in the mechanism shown in Fig. 1 and pulled by pulleys through the guide pipe. The ionization chamber, placed inside the lead shield, has been used for the 


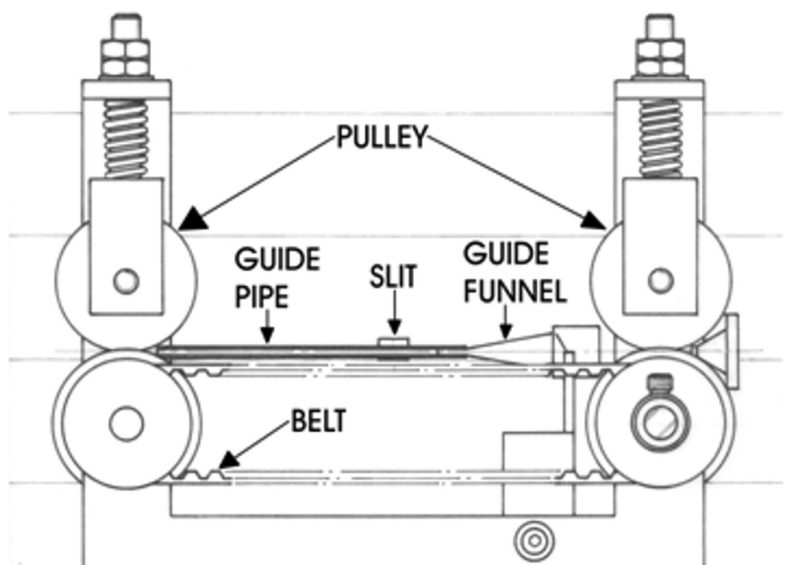

Fig. 1. Iridium-192 traction mechanism.

determination of distribution of activity along the irradiated wire. In the lead shield of ionization chamber there is a conical slit. The slit has the dimensions of $10 \mathrm{~mm}$ in width and $5 \mathrm{~mm}$ in height near the position of the wire, and its width increases by an angle of $20^{\circ}$, as shown in Fig. 2. The ionization chamber "sees" only $10 \mathrm{~mm}$ iridium-192 wire through the slit. This ionization chamber is fed with a $300 \mathrm{~V}$ source voltage (Canberra, model 3002D). The chamber is also connected to a Keithley electrometer model 617. The device counts the charge produced by ionizing radiation and derived from the piece of iridium-192 wire, that is opposite to the slit. The charge is counted every $2 \mathrm{~min}$. Three passages of wire are performed by pulleys and, with each performed pass the charge along the wire is measured. In view of the expression no maximum or minimum reading of the charge, the difference in relation to the average value of the readings along the wire should not exceed $10 \%$. This procedure is called the quality control of iridium-192 wire used in brachytherapy, which aims at verifying the homogeneity of the wire, with respect to the activity, along its $50 \mathrm{~cm}$ length. Variations in the activity of the wire along its length are most often caused by irregularities in the concentration of iridium. The homogeneity of radioactivity along the wire, will guarantee the homogeneity of dose in the treatment site.

After quality control, the activity of wires were measured in the ionization chamber (Capintec, model CRC-15R).

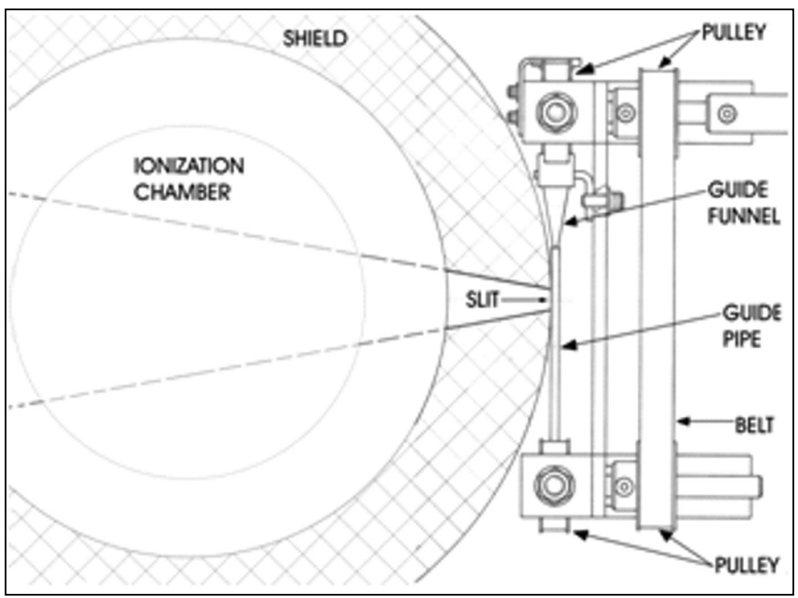

Fig. 2. Ionization chamber and shielding.

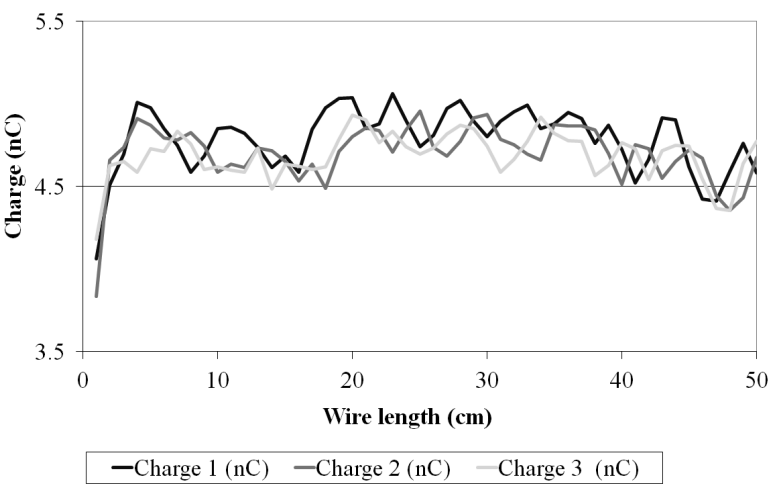

Fig. 3. Measurement of the charge along the Ir-192 wire 1.

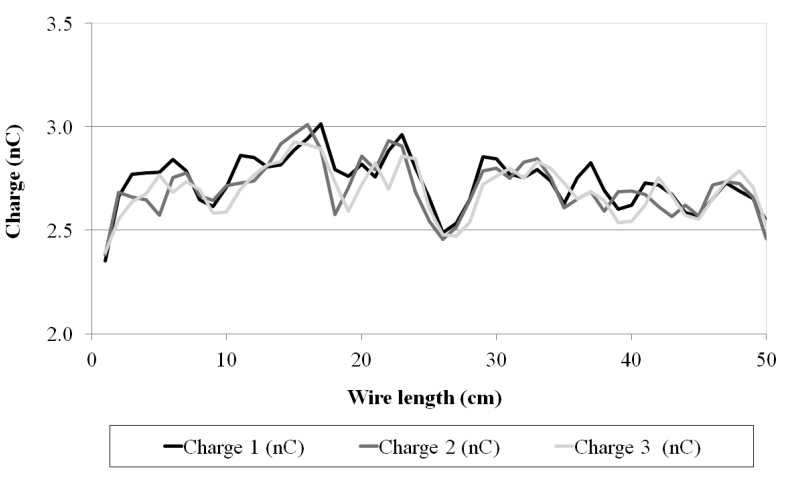

Fig. 4. Measurement of the charge along the Ir-192 wire 2.

\section{Results and discussion}

Analyzing the graphs of the charge measurement along the iridium wires 1 and 2 (Figs. 3 and 4), we note that there is a decrease of peak height values in the second and third measurement in relation to the first measurement. This can also be verified by variation of the means of measurements shown in Table 1. Rostelato et al. [4] also present values of this type of variation in their study about the production of radioactive sources. There is also a gradual decrease of the values of standard deviations of the wire 1 , while the wire 2 had its standard deviation values increased slightly in the second measurement and then return to the same level in the third measurement is observed. The maximum and minimum values of the wire had a downward trend when compared with the arithmetic mean of the measurements. In the case of wire 2, maximum and minimum values showed an oscillating behaviour similar to the standard deviations.

The irregularities in the concentration of iridium along the wire cause variations in the activity along its length. However, such irregularities cannot explain the decrease of the peaks read, averages and standard deviations in the measurement sequences. These variations are related to two main factors:

1. The internal diameter of guide pipe, which provides the passage of radiation toward the detector, is much larger than the iridium wire diameter (iridium wire is $0.3 \mathrm{~mm}$ in diameter, while the guide pipe is $2 \mathrm{~mm}$ in diameter).

2. The iridium wire reaches the hotcell in the helical form.

The iridium wire will lose its curl on its shape as it passes between the pulleys, which position the wire for 
Table 1. Results from evaluation of homogeneity of wires

\begin{tabular}{|c|c|c|c|}
\hline & Wire 1 & Wire 2 & Rostelato et al. [4] wire \\
\hline Average 1 & $4.801 \mathrm{nC}$ & $2.741 \mathrm{nC}$ & $2.2056 \mathrm{nC}$ \\
\hline Average 2 & $4.719 \mathrm{nC}$ & $2.711 \mathrm{nC}$ & $2.0228 \mathrm{nC}$ \\
\hline Average 3 & $4.697 \mathrm{nC}$ & $2.697 \mathrm{nC}$ & $1.9230 \mathrm{nC}$ \\
\hline $\mathrm{SD}^{\mathrm{a}} 1$ & $0.166 \mathrm{nC}$ & $0.114 \mathrm{nC}$ & \\
\hline SD 2 & $0.135 \mathrm{nC}$ & $0.125 \mathrm{nC}$ & \\
\hline SD 3 & $0.126 \mathrm{nC}$ & $0.115 \mathrm{nC}$ & \\
\hline Higher measure 1 & $5.4 \%$ & $10.0 \%$ & \\
\hline Higher measure 2 & $5.0 \%$ & $11.0 \%$ & \\
\hline Higher measure 3 & $4.9 \%$ & $8.4 \%$ & \\
\hline Lower measure 1 & $8.1 \%$ & $9.2 \%$ & \\
\hline Lower measure 2 & $7.7 \%$ & $9.4 \%$ & \\
\hline Lower measure 3 & $7.3 \%$ & $8.3 \%$ & \\
\hline Activity & $244.0 \mathrm{mCi}$ & $143.5 \mathrm{mCi}$ & \\
\hline
\end{tabular}

${ }^{\mathrm{a} S D}$ - standard deviation.

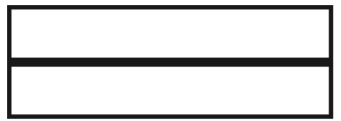

STRAIGHT

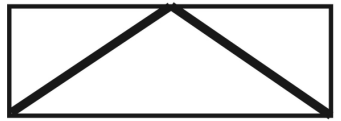

SAWTOOTH

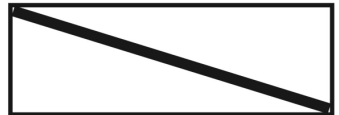

RAMP

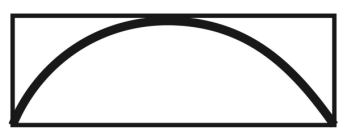

HILL
Fig. 5. Iridium wire profile in front of the slit.

measurement, losing their rolling shape, the length of wire that the detector sees through the slit goes down and, thus, the measured value also decreases.

In Fig. 5 are shown four examples of profiles, which can take iridium wire in front of the slit.

Setting the wire "visible" width as $10 \mathrm{~mm}$ and maximum height to $2 \mathrm{~mm}$, we can calculate the approximate values of the lengths of the four profiles shown in Fig. 5: a) straight profile - $10 \mathrm{~mm}$ long;

b) ramp profile - given a right triangle, base $10 \mathrm{~mm}$ and height of $2 \mathrm{~mm}$, we get a result of $10.198 \mathrm{~mm}$ in length, a difference of $1.98 \%$ compared to the ideal profile;

c) sawtooth profile - considering an isosceles triangle of base 10 and height $2 \mathrm{~mm}$, we obtain a result of $10.77 \mathrm{~mm}$, a difference of $7.7 \%$ compared to the ideal profile;

d) hill profile - considering the following sinusoidal function $x=t ; y=\{(\pi / 5) \cdot \sin t, t \in[0, \pi]\}$, to calculate the length of the wire we get the following line integral:

$$
\int_{0}^{\pi} \sqrt{1+\frac{\pi^{2} \cos ^{2} t}{25} \cdot d t}
$$

through the software Calculus Tools [5] we got the result 3.43, as the interval between 0 and $\pi$ is equivalent to the interval between 0 and $10 \mathrm{~mm}$, we obtain the length of the wire as $10.92 \mathrm{~mm}$, the difference being $9.2 \%$ compared to the ideal profile.

In the examples presented profiles we obtained a variation of wire length ranging from 1.98 to $9.2 \%$, values that influence too much the end result of iridium-192 wire quality control. Therefore, it is necessary to establish measures to restrict this type of variation. By continuing the use of the same system of pulleys employing the method push-pull wire, it is necessary that before the measurements, the wire loses its wavy shape, and also should avoid creasing. New projects of traction should aim to keep the wire as taut as possible in front of the slit, using the guide tube with an internal diameter smaller, or stretch the wire through the clamps that attach at their ends. Thus, it is possible to minimize the effect that the geometry of the source causes the reading and thus improve the quality control of the iridium-192 wire used in LDR brachytherapy.

\section{Conclusion}

The current method of quality control of the iridium-192 wire used in LDR brachytherapy shows systematic errors that directly influence the final result of the wire accordance. These errors can be minimized by procedures that allow the wire stays as straight as possible in front of the slit, without deviation, folds or sinusoids. Innovative projects about traction should aim at the wire stays as taut as possible in front of the slit.

\section{References}

1. Aird, E. G., Williams, J. R., \& Rembowska, A. (2000). Brachytherapy. In J. R. Williams, \& D. I. Thwaites (Eds.), Radiotherapy physics in practice (2nd ed., pp. 187-226). Oxford: Oxford University Press.

2. Khan, F. M. (1994). The physics of radiation therapy. Baltimore: Williams \& Wilkins.

3. Rostelato, M. E. C. M. (1997). Preparação de fontes de irídio-192 para uso em braquiterapia. Unpublished master's thesis, Nuclear and Energy Research Institute, São Paulo, Brazil

4. Rostelato, M. E. C. M., Rela, P. R., Zeituni, C. A., Feher, A., Manzoli, J. E., Moura, J. A., Moura, E. S., \& Silva, C. P. G. (2008). Development and production of radioactive sources used for cancer treatment in Brazil. Nukleonika, 53(S2), S99-S103.

5. McSherry, A. (2013, August 12). Calculus Tools for Android (Version 1.2.1) [Software]. Retrieved from http://market.android.com/details? id=com.andymc. derivative \&feature $=$ search_result. 